\title{
EFFECTS OF ACUTE AND CHRONIC INANITION UPON THE RELATIVE WEIGHTS OF THE VARIOUS ORGANS AND SYSTEMS OF ADULT ALBINO RATS
}

\author{
C. M. JACKSON
}

The Institute of Anatomy, University of Minnesota. Minneapolis

TWO PIGURES

CONTENTS

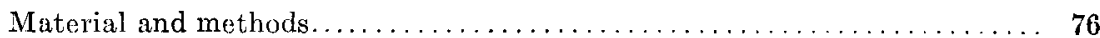

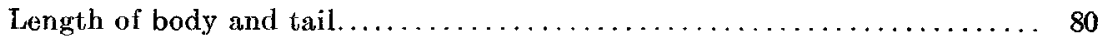

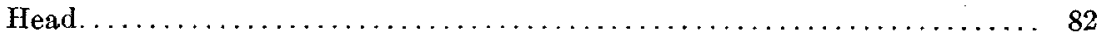

Extremities and trunk................................. 84

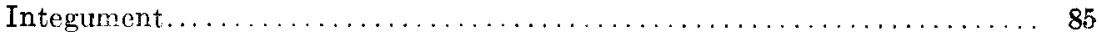

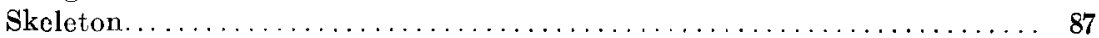

Musculature ........................................ 90

Viscera and 'remainder'.................................... 91

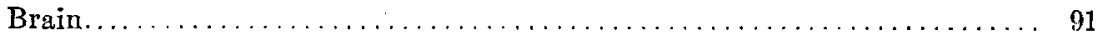

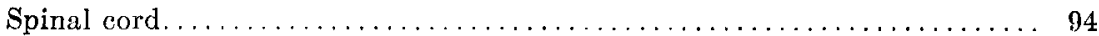

Eyeballs.............................................. 95

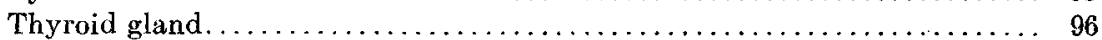

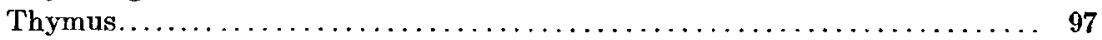

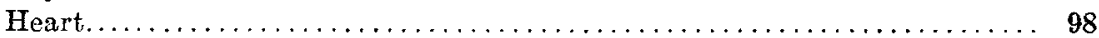

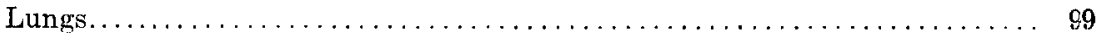

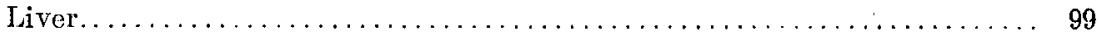

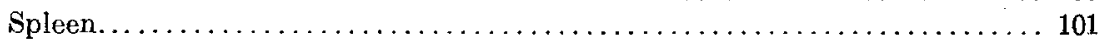

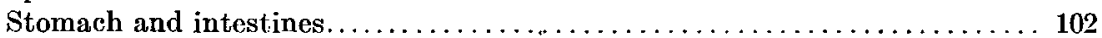

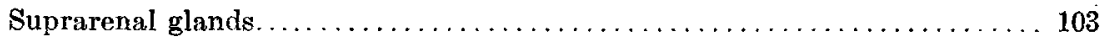

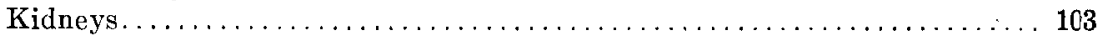

Gonads................................................ 104

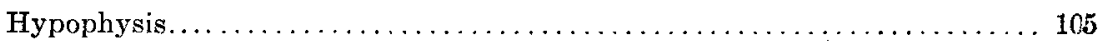

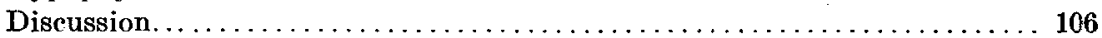

Summary ............................................... 107

Literature eited ........................................ 109

As emphasized by the author in a previous paper (Jackson '13), there is great need of a series of comprehensive growth norms, which would serve as a basis for experimental work and give a better insight into the growth process in animals. Through the 
investigations of Donaldson, Hatai, Jackson, Lowrey and others, considerable progress has been made toward the establishment of a growth norm for the albino rat. Since the normal growth process and the relative weights of the organs are frequently modified by malnutrition from various (sometimes unsuspected) causes, it is clearly of great importance to know the effects produced by inanition. In drawing conclusions from the results of any experiment upon animals, the possible effect of inanition should always be kept in mind. The present investigation upon this subject, which was begun at the University of Missouri, has been continued at the University of Minnesota with the aid of a special grant from the research fund of the Graduate School. The grant was used to employ a research assistant, who cared for the animals and assisted in the dissections, weighings, calculations, etc.

\section{MATERIAL AND METHODS}

The material included 21 well-nourished adult albino rats (Mus Norvegicus albinus) of unknown age. Two of these (O 5 and $\mathrm{O}$ 6) were derived from the Missouri colony and 19 from a local Minnesota stock. Of the 21, 4 were females and 17 males. They had been fed chiefly upon grain (oats and corn) with occasional meat and vegetables, and were placed upon a bread and milk diet for some days before beginning the experiment. During the experiment they were kept in cages with wire-net bottoms, allowing the feces (which might otherwise be eaten) to drop through.

Fifteen of the rats were used for the acute inanition experiment. They were allowed plenty of water, but no food otherwise. They were weighed daily and the individual records kept. The initial body weights varied from 182 to 367 grams (table 3 ). They were killed after 6 to 12 (average 9 ) days, ${ }^{1}$ the total loss in body weight varying from 25 to 39 per cent (average loss,

${ }^{-1}$ Bell ('11) found that the wild brown (Norway?) rat in captivity would live only 3 or 4 days, with loss of 25 or 30 per cent in body weight, when water is supplied but food withheld. Among animals in general, the older or larger are able to withstand inanition longer than the younger or smaller animals, probably on account of less rapid metabolism in the former. 
about 33 per cent). This represents moderately severe, but not extreme inanition, as a well-nourished adult albino rat will probably lose 40 per cent of his body weight before death, if kept warm. When pushed to the extreme, however, the rat is likely to die unexpectedly, with undesirable post mortem changes. These might affect not only the structure but also the weight of the organs, through congestion and coagulation of blood, and should therefore be avoided. Three of the rats included (table 3 , rats Nos. M 9, M 13, and S 28) were found dead, and in this case merely the weights of the head, extremities, integument, skeleton and musculature (which did not appear to be materially affected) are recorded.

In the rats subjected to acute inanition, the daily loss in body weight was fairly uniform in some individuals, but varied greatly in others. As might be expected, the loss is usually (though not invariably) greatest on the first day of the experiment, probably due to the reduction in contents of the stomach and intestines. In most cases (11 out of 15) the loss in body weight is greater during the first half than during the second half of the experiment, though the difference is usually slight. There is no constant relation between the percentage loss in body weight and either the initial body weight or the length of the inanition period. In general, the loss in body weight of albino rats during acute inanition is very similar in extent and variations to that found by Chossat ('43) for pigeons. Chossat demonstrated that the loss in body weight is greatest in the first third of the inanition period, slightly less in the last third, and considerably less in the middle third.

In order to compare the results of chronic inanition, 6 rats (all males) were fed upon a bread and milk diet gradually decreased in amount, so as to reduce the body weight about 1 per cent (of the initial weight) daily. Water ad libitum was also supplied. This was continued until the loss in body weight amounted to an average of about 36 per cent, which required about 5 weeks (table 3). The amount of food (entire wheat (Graham) bread soaked in whole milk), required for this purpose varied somewhat in individuals, but was approximately 10 per 
cent of the body weight daily. This is usually found insufficient for the maintenance of body weight in adult albino rats at ordinary room temperature. One rat (No. M 4) was found dead; the others were killed.

At the end of the experiment, in both acute and chronic inanition, the rats were killed by chloroform and the various organs and parts carefully dissected and weighed. The technique followed is that described by Jackson ('13) and Jackson and Lowrey ('12). The skeleton was first prepared as heretofore by carefully dissecting off the musculature, leaving the periosteum, ligaments and cartilages intact. This is recorded as 'ligamentous skeleton.' In most cases the periosteum and ligaments were then removed by maceration for about one hour in 1 per cent 'gold dust' solution, following which the bones were cleaned under water with forceps and camel's hair brush. ${ }^{2}$ So far as possible, the cartilages, including the intervertebral disks, were left intact and included with the skeleton. The skeleton was then taken from the water (excess moisture removed by filter paper) and weighed as 'cartilaginous skeleton.' The skeleton was then dried for 30 days in a dust-proof case at ordinary room temperature. This was found insufficient to remove all moisture, so the skeletons were finally dried several days in an oven at about $90^{\circ} \mathrm{C}$., until a constant weight was reached.

Portions of the various tissues and organs were preserved for histological study, which will be considered in a later paper.

As heretofore, in calculating the percentage weights, the net body weight (gross body weight less intestinal contents) is taken. The percentage weights of the organs are therefore slightly higher than they would be if calculated upon the basis of the gross body weight, but the difference is usually negligible, as the intestinal contents form only 2 or 3 per cent of the body weight during inanition.

2 For this method of preparing the cartilaginous skeleton, I am indebted to Professor Donaldson of The Wistar Institute. He states (in a personal communication) that the fresh skeleton is apparently slightly reduced (about 3 per cent) in weight by the 'gold dust' treatment, but this difference is so small as to be practically negligible. 
For purposes of comparison, the previous observations upon the normal weights of the various organs of the albino rat by Donaldson ('09), Hatai ('13), Jackson ('13) and Jackson and Lowrey ('12) were utilized. Some unpublished data from the Missouri Agricultural Experiment Station upon a series of six steers, varying from very fat to thin, are cited through the courtesy of Professors Trowbridge and Moulton.

The averages given in table 3 are the arithmetical means of the corresponding individual observations in the acute and the chronic inanition series, respectively. In estimating the normals at corresponding initial body weights for comparison, however, merely the averages were used. That is, the absolute weight of each organ corresponding to the average body weight was estimated (from data already available for the normal rat), and the corresponding percentage weight calculated. This is not quite so accurate as it would have been if the corresponding normal for each individual had been estimated, and the mean of these taken for comparison with the averages in the acute and chronic inanition series. However, the difference is slight and apparently not suff.cient in the present series to justify the more laborious method of making the individual estimates.

In view of the comparatively small number of observations, and the known variability, especially of some of the organs (Jackson '13), the conclusions reached in the present paper are by no means to be considered as final. It is believed, however, that they are sufficient to give an approximate idea of some of the more obvious and important changes in weight during inanition. As such they may be useful, even though limited in number, and may lead to further and more extensive investigations in the case of various individual organs. In general, the amount of variation found is sufficient to demand the exercise of caution in drawing conclusions from an insufficient number of observations, as is sometimes done in experimental work.

Although the literature on the subject of inanition is extremely large, comparatively few specific data directly bearing upon the question of the changes in the weight of the various organs are to be found. These are referred to later under the 
appropriate headings. Papers dealing merely with histological changes are usually not mentioned. Extensive references to the literature on inanition will be found in the articles by Morgulis ('11) and Mühlmann ('99).

\section{LENGTH OF BODY AND TAIL}

With reference to the body weight compared to the body (nose-anus) length at the end of the inanition period, the normal relations as determined by Donaldson ('09) were used for comparison. As might be expected, the body weight following inanition, both acute and chronic, is found to be lower than normal for corresponding trunk length, since the skeleton is known to be in general but slightly affected by inanition. The difference, however, is surprisingly small. It is a noteworthy fact that the initial body weight of the animals used in he experi-

TABLE 1

\begin{tabular}{|c|c|c|}
\hline & \begin{tabular}{|l|l|} 
ACUTE \\
INANITION \\
SERIES: \\
GRAMS \\
\end{tabular} & \begin{tabular}{|l} 
CHRONIC \\
INANITION \\
SERIES: \\
GRAMS \\
\end{tabular} \\
\hline $\begin{array}{l}\text { Normal gross body weight (theoretical, Donaldson) corre- } \\
\text { sponding to body length at end of inanition period, average } \\
\text { (from individual calculations)....................... }\end{array}$ & 191 & 147 \\
\hline $\begin{array}{l}\text { Actual gross body weight found at beginning of the inani- } \\
\text { tion period, average }(\operatorname{table} 1) \ldots \ldots \ldots \ldots \ldots \ldots \ldots \ldots\end{array}$ & 255 & 214 \\
\hline 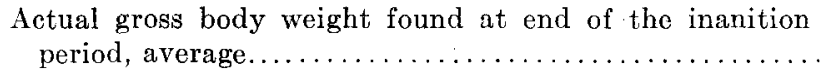 & 170 & 136 \\
\hline
\end{tabular}

ments is far greater than that normal for the body length at the end of the inanition period. (The length cannot be accurately measured in the living animal without anestheties at the beginning of the experiment.)

Thus, as shown in table 1, the body length at the end of the inanition period corresponds to a body weight much nearer to the final than to the initial weight of the animals subjected to inanition.

There are two possible explanations for this surprisingly close approach to the normal in the body weight after inanition. It is possible that the rats at the beginning of the experiment were 
somewhat too heavy for the normal at corresponding body length. This might account for the result, even on the assumption that the body length has remained constant during the period of inanition. On the other hand, it is more probable that there has been an actual slight decrease in the trunk length during inanition (probably due to shrinkage of the intervertebral disks), which would equally well account for the facts observed. Individual variations must also be kept in mind, as well as the possibility that the normal ratio of body weight to body length in the strain of rats used may differ somewhat from the normal, as determined by Donaldson.

The theory of a decrease in the trunk length during inanition is strengthened by the apparently changed ratio of tail length to body length. In a separate paper (Jackson '15) I have shown that the normal ratio of the tail length to body length in the albino rat increases from an average of about 0.36 in the newborn to 0.88 at 6 weeks (body weight 50 grams), decreasing slowly to about 0.85 at a body weight of 200 grams and to about 0.80 at 300 grams. (The lower ratio found in the heavier rats is partly due to the absence of females, in which the tail averages relatively longer than in the males.) Thus it appears that in rats with body weights corresponding to the initial weights in the inanition series, the normal average ratio of tail length to body length should be between 0.80 and 0.85 . It is impracticable to make the actual measurements on the living animals, although this might be done by the use of anesthetics. The data given in table 3 show that at the end of the inanition period, however, the average ratio in the acute inanition series is 0.93 , and in the chronic inanition series, 0.97. Thus it appears that inanition in adult albino rats tends to produce relatively longtailed individuals, due probably to a shrinkage in the trunk length.

Hatai ('08) reached the opposite conclusion, viz., that underfeeding produces short-tailed individuals; but his observations were upon younger, growing rats, in which the conditions might be somewhat different. Morgulis ('11) in the salamander, Diemyctylus, likewise found a greater shrinkage in the tail during inanition, while Harms ('09) found the converse to be true in 
Triton. This question is discussed more fully in the paper above referred to (Jackson '15), the conclusion being that inanition in young rats also tends to produce relatively long-tailed individuals.

\section{HEAD}

The head ( $\mathrm{fg} .1$; table 3 ) in acute inanition averages about 11.2 per cent of the body weight, varying from 10 per cent in the larger rats to 13.9 per cent in the smaller. Normally (Jackson '13; Jackson and Iowrey '12) in rats corresponding to the body weight at the beginning of the experiment, the head should range from about 8 per cent in the larger rats to 10 per cent in the smaller, the average for the group being about 9 per cent. Thus we may assume that during the period of acute inanition the head has increased from an average of about 9 per cent to about $\mathbf{1 1 . 2}$ per cent of the body. T his is an increase of about one-fourth in the relative size of the head.

Since the whole body has lost an average of one-third in absolute weight, it might appear at frst glance that the head has remained nearly constant in absolute weight. This, however, is not true. If the body weight decreased one-third while the head remained constant in absolute weight, the relative (percentage) weight of the head would increase in the ratio of 2:3 or from 9 to $13 \frac{1}{2}$ per cent. A study of the absolute weights of the head, compared with the normal, at the beginning of the experiment shows that the head has actually lost weight, but in much smaller proportion than the body as a whole. This is what is to be expected since, as will be shown later, the brain, eyeballs and skeleton in general lose but little or none in absolute weight during inanition; while the loss in fat (some of which is on the head) is great, and the loss in the integument and musculature is in nearly the same proportion as in the body as a whole.

The head of the 6 rats subjected to chronic inanition averages 11.4 per cent of the body weight, slightly higher than in acute inanition. The rats used in chronic inanition averaged smaller in body weight (table 3 ), and the normal relative initial weight of their heads should therefore be slightly higher, about 10 per cent (instead of 9 per cent, as in the acute inanition group). 


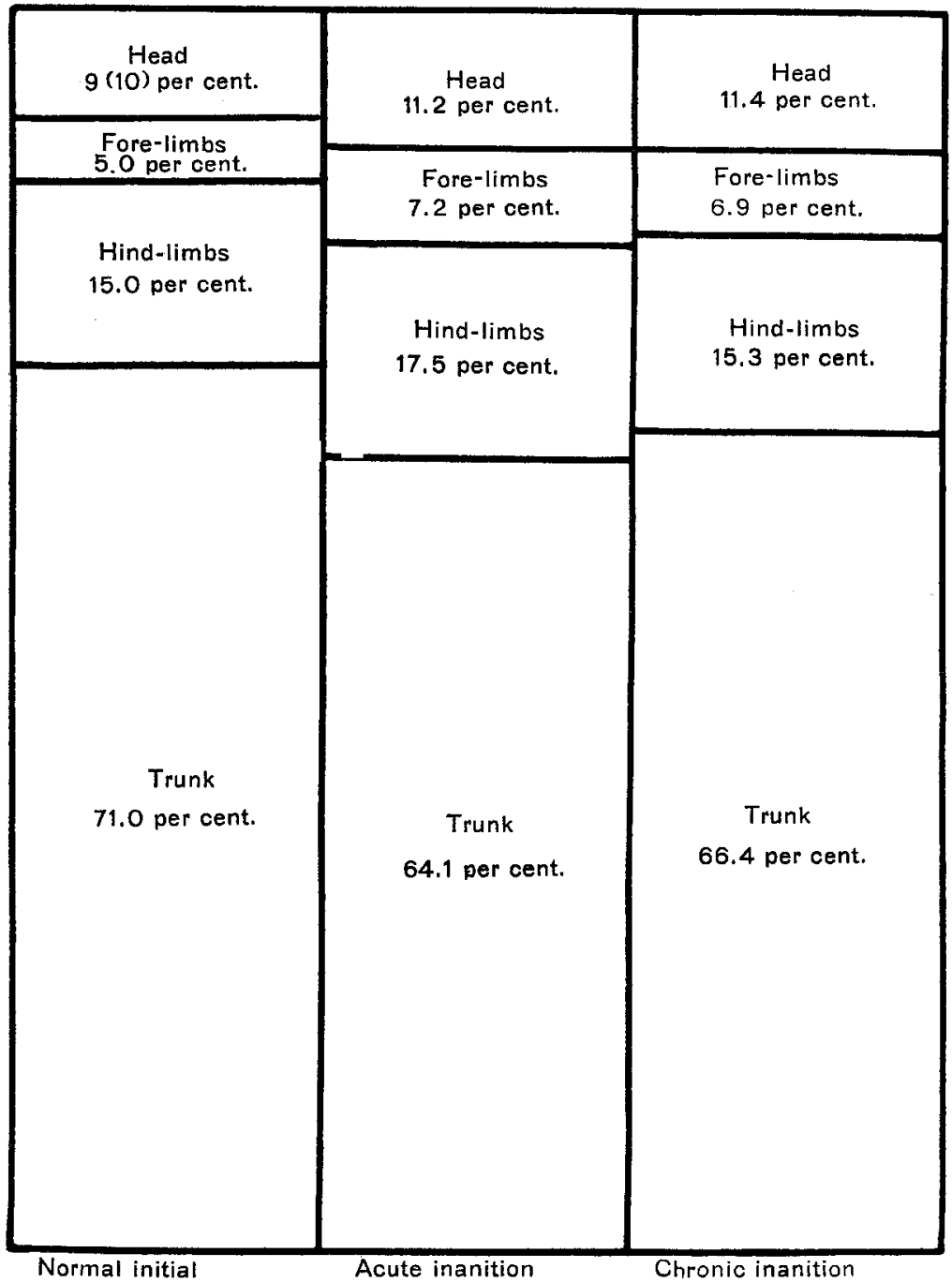

Fig. 1 Diagram representing the relative (percentage) weights of the head, trunk and extremities of adult albino rats. The first column represents the relations found in normal rats corresponding to the average initial body weight of those used in the experiments. The second column represents the relations found in the acute inanition series, and the third column those found in the chronic inanition series. 


\section{EXTREMITIES AND TRUNK}

The extremities were separated from the trunk at the shoulder and hip-joints, respectively. From figure 1 and table 3 it is seen that the fore limbs formed an average of 7.2 per cent of the body in the acute inanition series, and 6.9 per cent in the chronic inanition series. According to Jackson and Lowrey ('12), in the normal adult rat the fore limbs form about 5 per cent of the body. Consequently it would appear that there has been a relative increase in the weight of the fore.limbs during inanition, especially during acute inanition. This increase is greater than would be expected, since (as will appear later) the skeleton is the only important constituent of the limbs which increases in relative weight during inanition, the integument and musculature remaining relatively constant. The conclusion as to the forelimbs should be regarded as uncertain, however, because of: (1) the difficulty in separating the limbs (especially the skin) in a uniform manner; (2) the comparatively small number of observations upon which both the normal and the experimental average is based; (3) the apparent lack of agreement between the results for the entire fore limbs and for their components, skin, skeleton and musculature. It is possible, on the other hand, that the losses for skin, skeleton and musculature are not uniform in all parts of the body. Chossat ('13) has shown, for example, that the great pectoral muscles in pigeons lose relatively much more than the remainder of the musculature during inanition.

The hind limbs (fig. 1; table 3) in the normal adult form about 15 per cent of the body (Jackson and Lowrey). As might be expected, this is slightly increased, to 17.5 per cent, in the acute inanition series, probably on account of the relatively heavier skeleton. In the chronic inanition series, the hind limbs average 15.3 per cent, or about the same as normal. This may be explained as due to the relatively greater loss in the integument and musculature during chronic inanition (as will be shown later), this loss tending to counterbalance the relative increase in the skeleton.

The trunk (fig. 1; table 3) is measured by substracting the weight of the head and extremities from the net body weight. 
It forms normally about 0.71 per cent of the adult body (Jackson and Lowrey). During inanition, the trunk becomes relatively smaller, averaging 64.6 per cent in the acute inanition series (64.1 per cent, corresponding to the average of 11.2 per cent for the head in a larger series), and 66.4 per cent in the chronic inanition series. The relative decrease in the trunk of course counterbalances the relative increase in the head and extremities.

\section{INTEGUMENT}

As shown in figure 2 and table 3, the integument (which includes the skin and appendages, hair and claws) is fairly uniform in its relative weight, averaging 18.9 per cent in acute inanition (or 19.1 per cent in those cases in which the viscera were weighed), and 17.8 per cent in ehronic inanition. The average integument for normal adults (fig. 2) corresponding to the initial size of these rats forms about 18 per cent of the body weight (Jackson and Lowrey '12). It is therefore evident that during both acute and chronic inanition in adult albino rats the loss in weight of the integument is nearly proportional to that of the body as a whole, so the relative (percentage) weight remains almost the same.

In absolute weight, the integument has apparently decreased from about 45.9 grams, the normal at the average initial body weight in the acute inanition series ( 255 grams), to an average of 31.6 grams, as shown in table 3. This would correspond to a loss of 31.2 per cent in the weight of the integument. In the chronic inanition series, the corresponding decrease is from 38.5 to 23.7 grams, a loss of 38.4 per cent. Apparently, therefore, the loss in the weight of the integument is relatively slightly greater during chronic than during acute inanition.

The data found in the literature concerning the relative loss of the integument during inanition are not in agreement. In the dog, Aron ('11) states that the skin loses relatively more than the muscles (therefore, more than the body as a whole); Voit ('05 b) cites data showing a relative increase in the (fat-free) skin; while Falck's ('54) data show the skin relatively unchanged in weight. In the rabbit and cat, observations by Pfeiffer ('87), Voit ('66) 


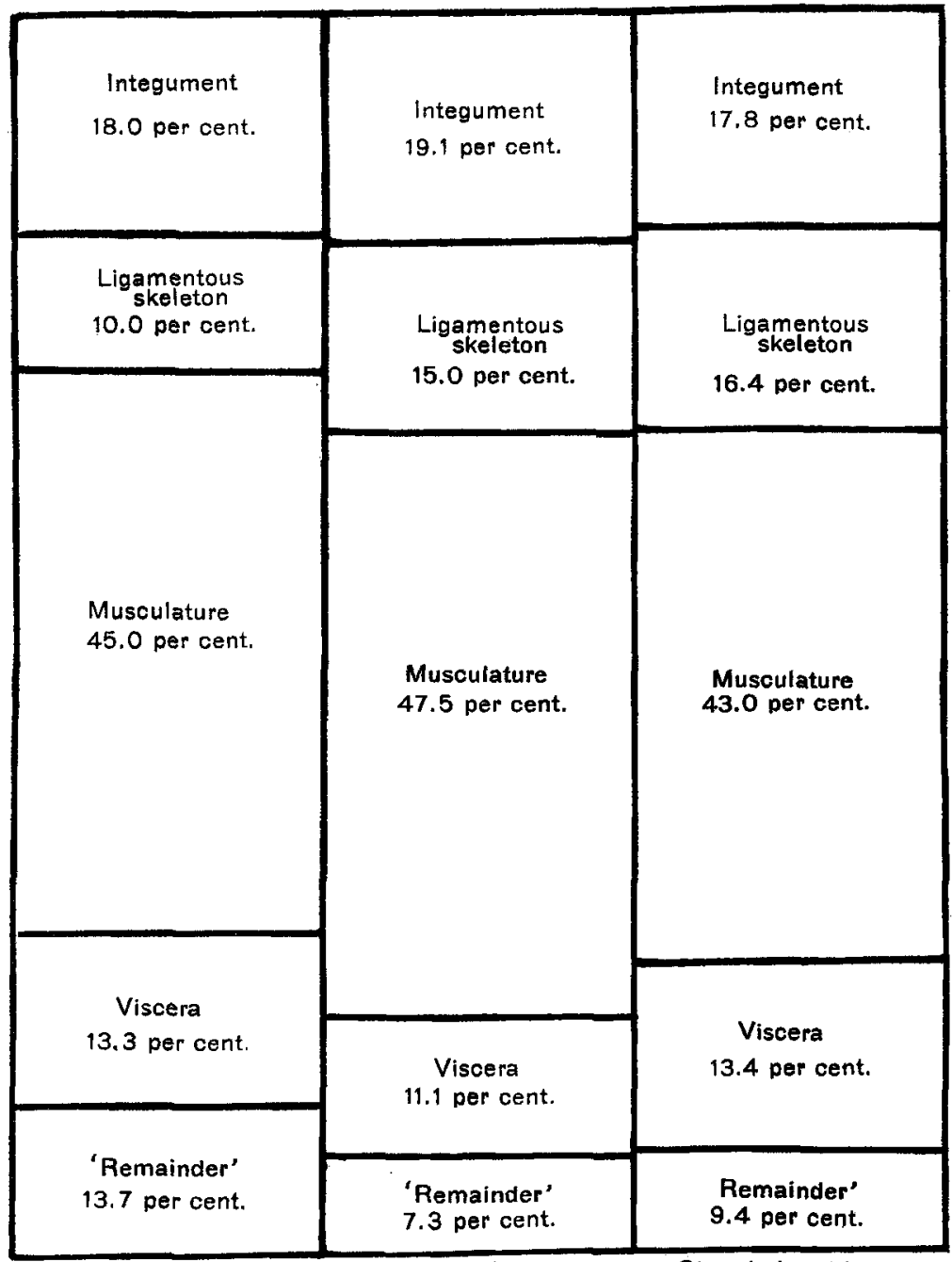

Normal initial

Acute inanition

Chronic inanition

Fig 2 Diagram representing the relative (percentage) weights of the various systems (integument, skeleton, musculature, viscera and 'remainder') of adult albino rats. The first column represents the relations found in normal rats corresponding to the average initial body weight of those used in the experiments. The second column represents the relations found in the acute inanition series, and the third column those found in the ehronic inanition series. 
and Sedlmair ('99) show a relative increase in the skin during inanition. Much of the variation is doubtless due to the differences in the relative amount of fat present in the integument of the normal animal. The subcutaneous fat is not abundant in the rat. Some unpublished data from the Missouri Agricultural Experiment Station upon a series of steers show that the percentage of the hide increases from 5.5 per cent in a very fat animal to 8.5 per cent of the body in a thin animal.

\section{SKELETON}

The ligamentous skeleton (table 3 ; fig. 2) forms an average of 15.3 per cent of the body after acute inanition (15.0 per cent in the series in which the viscera were weighed), and 16.4 per cent after chronic inanition. Since the average for the normal rat corresponding to the initial body weight of the animals used is only about 10 per cent of the body weight (Jackson and Lowrey '12), it is evident that while the body weight has decreased onethird during the period of inanition, the ligamentous skeleton has decreased little or none in absolute weight. If the normal skeleton formed 10 per cent of the body, and remained constant while the body lost one-third in weight, the relative weight of the skeleton would be increased one-half, or to 15.0 per cent. This corresponds with the observations as closely as could be expected.

In terms of absolute weight, assuming that the skeleton formed 10 per cent of the normal initial weight, the skeleton apparently decreased from 25.5 to 25.4 grams in the acute inanition series (loss of 0.4 per cent); and increased from 21.4 to 21.8 grams in the chronic inanition series (gain of 1.8 per cent). No great stress can be laid upon the accuracy of these figures, however, on account of the small number of observations, and the variability and uncertainty as to the normal weight.

The cartilaginous skeleton, including the bones and cartilages after removal of the ligaments by maceration (as previously described), forms an average of 10.9 per cent of the body in seven cases of acute inanition, and 12.4 per cent in the chronic inani- 
tion series (table 3). No published observations upon the normal cartilaginous skeleton are available for comparison. Professor Donaldson of The Wistar Institute, however, has very kindly sent me a series of observations upon the weight of the cartilaginous skeleton in normal albino rats. The average, in 10 cases with body weight varying from 194 to 426 grams, forms about 6.7 per cent of the (gross) body weight. In this series, however, I understand that the intervertebral cartilages were not preserved, so this figure is probably somewhat too low for use as a normal to be directly compared with my observations upon the cartilaginous skeleton in inanition. The normal adult cartilaginous skeleton, including the intervertebral cartilages, would probably form about 7 per cent (or slightly more) of the net body weight.

The dried cartilaginous skeleton (table 3 ) formed an average of 5.48 per cent of the net body weight in 7 cases of acute inanition, and 6.03 per cent in the 6 chronic cases. Thus it is evident that in each series the cartilaginous skeleton is composed of approximately half dry substances and half water. In the acute inanition series, the dry substance in the cartilaginous skeleton averages 50.5 per cent (range, 45.1 to 54.6 per cent). In the chronic series, the dry substance averages 49.2 per cent (range, 45.5 to 55.7 per cent). If case M 5 be excluded (which appears to be exceptional or erroneous), the average for the chronic series would be still lower, or 47.9 per cent. In any event, the dry content appears to be slightly lower and the water content correspondingly higher on the average in the chronic inanition series, which might be expected.

Data upon the normal composition of the skeleton of the rat for comparison are scarce. In one case which I have observed (at 10 weeks) the net body weight was 115 grams, ligamentous skeleton 9.91 per cent of body weight, fresh cartilaginous skeleton 5.57 per cent, and dry cartilaginous skeleton 2.97 per cent. In this case the dry substance formed 53.4 per cent of the cartilaginous skeleton. Lowrey ('13) in two albino rats (body weight 267.5 grams) finds the ligamentous skeleton forming about 9 per cent of the body weight, and containing 52.6 (52.1 to 53.1) 
per cent of dry substance. (This would probably be slightly higher than the dry content of the cartilaginous skeleton, however, on account of the higher percentage of water in the ligaments.) Further data are necessary before final conclusions can be reached, but it appears that in the rat (as in other animals) the percentage of water in the skeleton is increased during inanition.

It is a well known fact that in general the skeleton loses comparatively little during inanition, and thus increases greatly in relative (percentage) weight. In a series of six steers, the skeleton varied from 10.6 per cent of the body in a very fat animal to 19.3 per cent in a thin animal. (Data from the Missouri Agricultural Experiment Station.) An apparent slight loss in absolute weight of the (cartilaginous?) skeleton has been observed during inanition as follows: pigeons, by Chossat ('43), 3 per cent; cats, by Voit ('66), 14 per cent; little or none by Sedlmair ('99); dogs, little or none by Voit ('05 a) and Falck ('54); rabbits, little or none by Gusmitta ('84), Weiske ('95) and Pfeiffer ('87).

Since the calcified framework is but little affected in volume during inanition, it is evident that there can be but little, if any, loss in absolute weight of the skeleton. It is at least theoretically possible that there may even be a slight increase in its weight, since the fat in the bone-marrow is replaced by a mucoid substance (Jackson '04) presumably of higher specific gravity. Examination of bones, therefore, invariably shows a marked increase in water content during inanition. As Sedlmair ('99) states (p. 33): "Es giebt kein einziges sicheres Beispiel für einen geringeren Wassergehalt der Knochen hungernder Tiere; alle Forscher (Chossat und Lukjanow an Tauben, Gusmitta, C. Voit und Schöndorff an Hunden, Weiske an Kaninchen) fanden darin einen höheren Wassergehalt." This would naturally vary in different bones, and in different animals, according to the relative fat content. Small animals, like the rat, have in general relatively much less marrow fat than larger animals. 


\section{MUSCULATURE}

The musculature (table 3 ; fig. 2) forms an average of 47.6 per cent of the body in the acute inanition series, which is slightly higher than the average for the normal adult rat (which is about 45 per cent, Jackson and Lowrey '12). The musculature in the chronic inanition series is somewhat lower, the average being 43.0 per cent of the body weight. This would indicate a somewhat greater loss relatively in chronic inanition.

In terms of absolute weight, the musculature would appear to have decreased from 114.75 to 79.25 grams (a loss of 30.9 per cent) in the acute inanition series; and from 96.30 to 57.0 grams (a loss of 40.8 per cent) in the chronic inanition series.

There is much variation in the weight of the musculature following inanition, judging from data available in the literature. The statements usually refer to acute inanition. According to Gaglio ('84), while the body weight of the frog loses 56 per cent the musculature loses 85 per cent of its weight. The musculature appears to suffer a slight relative loss (decrease in percentage weight) in dogs (Falck '54; Voit '05 b) and cats (Sedlmair '99), while it remains nearly unchanged in the rabbit (Pfeiffer '87; Voit, '05 b). On the other hand, data from a series of steers slaughtered in the Missouri Agricultural Experiment Station indicate a relative increase in the musculature from about 33 per cent of the body weight in a very fat animal, to 44 per cent in a lean animal, due probably to the earlier loss of the fat. Voit (66) finds a slight relative increase in the musculature of the cat. Lasarew ('97) in an extensive series of guinea-pigs subjected to various degrees of inanition found that the loss of the musculature is somewhat less than that of the body fat in the earlier periods, but greater in the later periods. While the body weight lost 10 per cent, the musculature lost only 7.28 per cent of its weight; but the loss of the musculature was much greater at later periods. This would perhaps explain the relatively greater loss of the musculature during chronic inanition. 


\section{VISCERA AND REMAINDER}

The average for the total visceral group in the normal adult rat, according to Jackson and Lowrey ('12; based upon only a few observations) is about 13.3 per cent $0^{\circ}$ the body weight. In the acute nanition series (table 3 ; fig. 2 ) the average found is 11.1 per cent; while $n$ the chronic series it is 13.4 per cent. This would seem to indicate that the loss in weight is relatively greater in acute than in chronic inanition. As a matter of fact, the great majority of the individual organs, as will be seen later, show a greater relative loss during chronic inanition. The liver and spleen are exceptions, however, and the large bulk of the former overbalances the other viscera when all are grouped together. On the whole, there is not much change in the relative weight of the visceral group; but there is, however, much variation among the individual organs, as will be seen later.

Aron ('11) states that the organs lose more than the musculature during inanition in dogs. Data by Voit ('05 b) show a decrease in the relative size of the viscera in the rabbit, but not much change in the dog.

The 'remainder' is the amount obtained by substracting from the net body weight the weight of the skin, skeleton, musculature and visceral group. It includes the loss by evaporation and escape of liquids, a few small unweighed organs, and the dissectable masses of fat. In the normal adult rat, the 'remainder' forms about 13 per cent of the body weight (Jackson and Lowrey '12). In the chronic inanition series, the average is 9.4 per cent. In the acute series the average is 7.3 per cent. The decrease in the relative weight of the 'remainder' is probably due chiefly to loss of fat.

\section{BRAIN}

The average for the brain in the acute inanition series (table 1 ) is 1.18 per cent of the body weight. By means of the tables and curves constructed by Donaldson ('09), the (theoretical) normal weight of the brain can be derived, corresponding to any given body weight. This gives an average of 0.78 per cent for the assumed normal weight of the brain at the beginning of the

THE AMERICAN JOURNAL OF ANATOMY, VOL. 18, NO. 1 
experiment (gross body weight, 244 grams). Since the average loss in body weight during the inanition period is one-third, it is evident that the brain has lost but little if any in absolute weight.

The theoretical average initial absolute weight of the brain is about 1.902 grams, forming 0.78 per cent of the (gross) body weight (Donaldson '09). According to Donaldson's ('08) table 1, the brain weight observed in six cases averaged 1.900 grams, the theoretical being 1.905 grams, at the body weight of 245 grams. If this absolute weight of the brain remained constant, while the body weight lost one-third (33.9 per cent), the final percentage weight of the brain would be increased about one-half, or to 1.17 per cent. The average absolute weight of the brain actually observed at the end of the period of acute inanition is 1.8046 grams, corresponding to an average of 1.18 per cent of the (net) body weight. ${ }^{3}$ This weight is slightly less than would be expeeted if the brain remained constant in absolute weight, indicating a loss of about 5.1 per cent in the absolute weight of the brain during inanition.

The observations upon the brain in chronic inanition (table 3 ) indicate a similar condition. The average brain in this series weighs 1.743 grams and forms an average of 1.33 per cent of the (net) body weight. (This is the mean of the individual percentages; 1.74 .3 grams would form 1.31 per cent of the average net body weight, 132.5 grams; or 1.28 per cent of the average corresponding gross body weight, 136 grams.) According to calculations from Donaldson's ('09) data, the average brain corresponding to the body weight at the beginning of the experiment (213.7 grams) should weigh 1.866 grams, forming about 0.87 per cent of the body weight (the percentage being higher than in the acute inanition series on account of the smaller average body weight). ${ }^{4}$ This is slightly higher than the result to be expected on the assumption that the absolute brain weight has remained

\footnotetext{
${ }^{3}$ This is the mean of the individual percentages, as shown in table 3 . The average brain weight, 1.8046 grams, would correspond to 1.13 per cent of the corresponding average gross body weight, 160 grams, at the end of the experiment.

1 According to Donaldson's ('08) table 1, corresponding to a body weight of 215 grams, the average of 8 brains, both sexes, was 1.873 grams, the corresponding theoretical weight by formula being 1.871 grams.
} 
constant, while the body weight has decreased about one-third (36.1 per cent). In other words, the results indicate a loss of about 6.6 per cent in the absolute weight of the brain during chronic inanition, which is slightly greater than the apparent loss (5.1 per cent) during acute inanition. A larger series of observations would be necessary, however, to draw any final conclusions with precision.

The data agree fairly well with the results of Hatai ('04) who found an estimated loss of about 5 per cent in the weight of the brain of young rats during chronic inanition. Donaldson ('11), however, found in still younger rats an actual increase of 3.6 per cent in the brain weight during chronic inanition (body weight held constant from age of 30 days to 51 days); while my own observations (Jackson '15) indicate little or no change in the brain weight under these conditions.

It has long been known that of all the organs of the body, the central nervous system apparently suffers least in weight (if at all) during inanition. Thus Chossat ('43) found no $\operatorname{loss}^{5}$ in the weight of the brain in starved pigeons, with loss in body weight of about 40 per cent. Falck ('54) in dogs, and Lasarew ('97) in guinea-pigs, found little or no loss in the weight of the brain and cord during inanition. Bowin ('80) and Pfeiffer ('87) found an absolute decrease (but relative increase) in the brain weight of the rabbit. Voit ('66) in cats found a decrease of about 3 per cent in the weight of brain and cord; while the data of Sedlmair ('99) would even indicate an actual increase in their weight during starvation. Data from a series of steers slaughtered in the Missouri Agricultural Experiment Station show that the absolute weight of the brain and cord in thin animals is but very slightly less than in very fat animals with nearly double the

\footnotetext{
${ }^{5}$ Since Chossat's results are often misquoted, it may be noted that he found the average weight of the brain almost identical in the 8 starved pigeons and in 8 controls of nearly the same (initial) body weight; (brain weight average 2.27 grams for starved; 2.25 grams for corresponding controls). On account of the difficulty in determining the exact plane of separation betwcen the brain and spinal cord, however, Chossat preferred to combine their weights, thus giving a slight decrease (about 1.9 per cent) in the absolute weight of the entire central nervous system during inanition.
} 
body weight. The relative (percentage) weight is of course correspondingly higher in the thin animals.

In young animals during the period of active growth, the results of inanition (especially chronic inanition) are in general somewhat different from those in adults, since the tendency of the organs to maintenance is in the young animal complicated by the growth impulse (Jackson '15). Bechterew ('95) found a slight apparent loss in the absolute weight of the brain and spinal cord of the newborn cat and dog during acute inanition. Hatai ('04) found in a series of young albino rats subjected to chronic inanition for 21 days an estimated average loss of about 5 per cent in the absolute weight of the brain. Later (Hatai '08) in another group of young rats in which growth had been retarded by underfeeding, he found that in these stunted animals the brain and cord had a weight approximately normal for the corresponding body weight. Donaldson ('11), in still younger rats held at nearly constant body weight by underfeeding from age of 30 days to 51 days, finds an apparent increase of 3.6 per cent in the weight of the brain. My own observations (Jackson '15), however, indicate little or no change in the weight of the brain under these conditions.

On the whole it appears that in adults inanition, both acute and chronic, produces a slight loss in the absolute weight of the brain. In young, rapidly growing animals, however, it is doubtful whether any such loss occurs, especially $\mathbf{n}$ chronic inanition, where there is even a possible increase in brain weight.

\section{SPINAL CORD}

The spinal cord in the acute inanition series (table 3 ) has an average weight of 0.631 gram and forms an average of 0.41 per cent of the body weight. Calculations from Donaldson's ('09) data indicate that at the average initial gross body weight (244 grams) the spinal cord should weight 0.625 gram, forming 0.26 per cent of the body weight. The data would therefore seem to indicate not only no loss, but even a very slight gain of the spinal cord in absolute weight during the period of acute inanition. In an earlier paper, Donaldson ('08) in table 4 gives 
the average weight of the spinal cord (at body weight of 245 grams) as 0.630 gram in 2 males, and 0.640 gram in 4 females. On the whole, therefore, we may conclude that the spinal cord during acute inanition undergoes little or no change in weight. Individual variations make comparisons with controls more or less uncertain, especially in a relatively small series of observations.

A somewhat different result is found in the chronic inanition series. Donaldson's ('09) data would indicate that the spinal cord in body weights corresponding to the average initial weight (214 grams) of this series would form an average weight of 0.593 gram or 0.28 per cent of the body weight. In an earlier paper, Donaldson ('08) in table 4 gives the weight of the spinal cord (at body weight of 215 grams) as averaging 0.590 gram in 5 males, and 0.630 gram in 3 females (corresponding theoretical weight by formula being $0.593 \mathrm{gram}$, sexes combined). The actual weight of the cord found at the end of the inanition period averages $0.569 \mathrm{gram}$, or about 0.43 per cent of the body weight. This would indicate a loss of about 4 per cent in the absolute weight of the spinal cord during chronic inanition. Thus in the spinal cord, as in the brain, there appears to be in the adult rat a tendency to greater loss in chronic than in acute inanition. In the young rat, however, this tendency is more than counterbalanced by the growth impulse, so that the spinal cord may gain in weight while the body weight is held constant (Donaldson '11; Jackson '15).

In any event, however, it is evident that the adult spinal cord, like the brain, shows but very slight if any loss in absolute weight during inanition, thus increasing markedly in relative (percentage) weight. This is in general agreement with the observations of Chossat ('43), Falck ('54), Lasarew ('97), Sedlmair ('99), Voit ('66), and Bechterew ('95) previously mentioned in the discussion of the brain.

\section{EYEBALLS}

The eyeballs in the acute inanition series (table 3) form an average of about 0.19 per cent of the body weight. In normal rats corresponding to their initial body weight, the average 
should be about 0.12 per cent (Jackson '13). Since the body weight has decreased about one-third (average 33.9 per cent) it is evident that the eyeballs must have remained nearly stationary in absolute weight, thus increasing their relative (percentage) weight by about one-half. In terms of absolute weight, there would appear to be a reduction from 0.298 gram (the theoretical weight corresponding to the initial body weight of 244 grams, according to Hatai '13) to 0.285 gram, the final average weight of the eyeballs (table 3). This would indicate a loss of 4.4 per cent.

A similar condition is found in the chronic inanition series. The eyeballs here form an average of about 0.20 per cent of the body weight, while the normal for the initial body weight averages about 0.13 per cent. (The higher figures in the chronic inanition series are due to the smaller initial body weight in this series.) Thus it is evident that, with a loss of about one-third (average 36.1 per cent) in the body weight during inanition, the absolute weight of the eyeballs has changed but little. In terms of absolute weight there would appear to be a reduction from about 0.280 gram (the theoretical weight corresponding to the average initial body weight of 214 grams, according to Hatai '13) to $0.2638 \mathrm{gram}$, the final average weight of the eyeballs (takle 3). This would correspond to a loss of 5.8 per cent in the weight of the eyeballs during chronic inanition.

That the eyeballs lose little or nothing in absolute weight during inanition, increasing proportionately in relative (percentage) weight, is also indicated by the data of Falck ('54) for the dog, and Sedlmair ('99) for the cat. Bitsch ('95) finds the (absolute) weight of the eyeballs in the dog usually increased during inanition, which he suggested may be due to oedema.

\section{THYROID GLAND}

The thyroid gland in the acute inanition series (table 3) forms an average of 0.023 per cent of the body weight. The normal for the initial body weights would average about 0.015 per cent (Jackson '13). Since the body weight has been reduced one-third during inanition, this would indicate that there has been no 
loss in the absolute weight of the thyroid gland. In terms of absolute weight, the thyroid gland after acute inanition averages 0.0380 gram, which is almost identical with the theoretical weight corresponding to the average initial body weight of 244 grams (Hatai '13).

The results in chronic inanition are somewhat different. Here the thyroid gland forms an average of about 0.020 per cent of the body weight, the normal for the corresponding initial body weights being about 0.016 per cent. In this case the thyroid gland has apparently lost weight during chronic inanition, though relatively less than the body as a whole. According to Hatai ('13) the weight of the thyroid gland corresponding to the average initial body weight of 214 grams would be about 0.034 gram. The final absolute weight averages $0.0266 \mathrm{gram}$, indicating a loss of about 21.8 per cent in chronic inanition.

On account of the variability of the thyroid gland, however, and the difficulty in dissecting it out accurately, no final conclusions can be drawn from the limited number of observations at hand. As in the case of the brain, spinal cord and eyeballs, however, there appears to be a greater tendency to loss in weight of the thyroid gland during chronic inanition.

Excepting the observations by Falck ('54), indicating no change in the relative (percentage) weight of the thyroid gland during inanition in the dog, no data on this subject have been found in the literature. Traina ('04) eites data, however, upon the histological changes.

\section{THYMUS}

It is already known that the thymus in the albino rat normally undergoes a diminution in weight (due to age involution) after the age of 10 weeks (Jackson '13) or more precisely 85 days (Hatai '14). At the age of one year, it forms normally about 0.020 per cent of the body (Jackson). The thymus in the present acute inanition series forms an average of about 0.020 per cent of the body weight, while in the chronic inanition series the average is 0.021 per cent (table 3 ). The age of the rats used in the inanition experiments is unknown, but from the 
body weight it is probable that few of them were less than a year old. Therefore while hunger is known to produce a marked involution of the thymus (Hammar), it is probable that in the present case the involution had already been produced by age, and was not caused by inanition. According to Jonson ('09), in young rabbits the weight curves of fat and thymus are similar in chronic inanition, but the fat decreases somewhat more rapidly in acute inanition.

\section{HEART}

The heart in the acute inanition series forms an average of about 0.43 per cent of the body weight, and about 0.42 per cent in the chronic inanition series (table 3 ). The normal for corresponding initial body weights would average about 0.43 per cent (Jackson '13) or about 0.38 per cent, according to Hatai's (13) data. Thus it is evident that the heart during inanition has lost weight nearly in the same proportion as the whole body.

Using Hatai's ('13) curves to determine the normal at corresponding initial body weights, the absolute weight of the heart apparently decreases from about 0.925 to 0.6687 gram (loss of 27.7 per cent) in the acute inanition series; and from about 0.830 to 0.5577 gram (loss of 32.8 per cent) in the chronic inanition series. As in the case of the viscera previously considered, the loss is apparently slightly greater relatively in chronic inanition.

The statements in the literature generally indicate that the heart during inanition loses somewhat less in weight than the body as a whole, and increases accordingly in relative (percentage) weight. This would appear to be the case in man (Aschoff '11; Lustig '02), cat (Voit '66; Sedlmair '99), newborn kitten (v. Bechterew'95) dog (Falck'54), guinea-pig (Lasarew '97), rabbit (Bowin '80), and in thin compared with fat steers (data from Missouri Agricultural Experiment Station). The data of Chossat ('43) for pigeons, however, would indicate a reduction in heart weight relatively slightly greater than in the body as a whole. 


\section{LUNGS}

The lungs of the rat are quite variable in weight, owing to the frequency of infection, which may affect their weight even when the lesions are slight. The average for the lungs in the acute inanition series is 0.61 per cent of the body weight, and 0.55 per cent in the chronic inanition series (table 3). Since the normal lungs corresponding to the average initial body weight form an average of about 0.60 per cent (Jackson '13), it appears (although the evidence is insufficient for final conclusions) that during inanition, both acute and chronic, in adult albino rats the lungs lose in weight in about the same proportion as the whole body, their relative (percentage) weight remaining nearly the same. Taking the normal weight of the lungs at corresponding body weights from Hatai's ('13) curve, there is apparently a decrease from about 1.40 to 0.968 gram (loss of 30.9 per cent) in the acute inanition series; and from about 1.24 to 0.743 gram (loss of 40 per cent) in the chronic series. Again, as in the case of the viscera previously considered, the loss appears relatively greater during chronic inanition.

Comparatively few data are found in the literature concerning the weight of the lungs in inanition. In pigeons, Chossat ('43) found a loss of 22.4 per cent in the lungs, compared with 40 per cent in the entire body weight. Thus their relative (percentage) weight is considerably increased, which was also observed by Voit ('66) and Sedlmair ('99) in the cat, and von Bechterew ('95) in newborn kitten. In the dog, however, Falck's ('54) data indicate a loss relatively slightly greater than that of the body, with a corresponding decrease in percentage weight.

\section{LIVER}

The liver in the acute inanition series (table 3) forms an average of about 2.88 per cent of the body weight. Since the normal for the corresponding initial body weights is about 4.5 per cent in the acute inanition series, and 4.3 per cent in the chronic (Jackson '13) it is evident that the liver has apparently lost in weight relatively more than the body as a whole. In the chronic 
inanition series, however, the weight of the liver is more variable, and the average (3.98 per cent) is but little below the normal. As the liver is normally subject to great individual variations in weight (Jackson '13), however, caution should beobserved in drawing final conclusions.

In terms of absolute weight, using my (Jackson '13) data for comparison, it appears that the liver decreases from about 10.98 to 4.587 grams (loss of 58 per cent) in the acute inanition series, and from 9.20 to 5.219 grams (loss of 43 per cent) in the chronic inanition series. It may also be remembered that in the series investigated by Hatai ('13), the average weight of the normal liver was found distinctly higher than in my series; and the loss in weight, estimated upon this basis, would be considerably greater.

With the exception of the adipose tissue, the thymus (in young animals) and occasionally the spleen, all investigators agree that the loss of weight in the liver is relatively greater than that in any other organ. Thus the liver decreases in relative (percentage) weight, as has been observed in man (Aschoff '11), white mouse (Cesa-Bianchi '09), pigeon (Chossat '43), rabbit (Pfeiffer '87), cat (Voit '66; Sedlmair '99), dog (Falck '54), newborn eat and $\operatorname{dog}$ ( $\mathrm{v}$. Bechterew '95), guinea-pig (Lasarew '97) and in thin steers, compared with fat (data from Missouri Agricultural Experiment Station). While the loss is practically always relatively greater than in the body as a whole, the amount of loss is quite variable.

Since the loss in weight of the liver (unlike all viscera previously considered) is relatively greater in acute inanition it seems probable that the greatest loss occurs during the earliest stages of inanition, when the liver yields its store of easily available food material (glycogen, fat, etc.). Thus Lasarew ('97) found that during the early period of inanition in the guineapig, while the body weight lost 10 per cent, the liver lost 18 per cent of its weight, or relatively near y twice as much. Toward the end of the inanition period, on the contrary, the liver apparently lost relatively only half as much as the whole body. 


\section{SPLEEN}

In the acute inanition series (table 3 ), the spleen forms an average of 0.21 per cent of the body. This is below the normal for the average corresponding initial body weight, in which case the average is 0.27 per cent. In the chronic inanition series, however, the average ( 0.30 per cent) is slightly higher than the normal (Jackson '13). The individuals in both acute and chronic inanition, however, are exceedingly variable, as seen in the table. This is also true of the normal spleen, which is one of the most variable organs in the body (Jackson '13). The number of observations is therefore insufficient for final conclusions concerning the effect of inanition upon the weight of the spleen in the albino rat.

In terms of absolute weight, taking Hatai's ('13) curve for the normal, there is apparently a decrease in the weight of the spleen from about 0.645 to 0.3177 gram (loss of 51 per cent) in the acute inanition series; and from 0.570 to 0.4056 gram (loss of 29 per cent) in the chronic series.

That the spleen loses heavily during inanition, losing in relative as well as absolute weight, has been found in man (Aschoff '11; Stschastny '98), pigeon (Chossat '43), rabbit (Bowin '80), and cat (Voit '66; Sedlmair '99); while a decrease less marked than in the whole body (relative increase) appears in the dog (Falck '54) and in thin steers, compared with fat (data from Missouri Agricultural Experiment Station). Data from von Bechterew ('95) indicate a relative increase in the spleen of newborn kittens during inanition, but a decrease in puppies. These apparently conflicting statements are perhaps to be explained largely by the great variability of the spleen, making comparison with controls uncertain. In addition, however, there is the possibility that the loss in the spleen may vary according: to the character and stage of inanition. Thus Lasarew ('97) in the guinea-pig found the greatest loss in weight of the spleen to occur in the middle period of inanition (second period of 10 per cent loss in body weight), during which the spleen lost 31 per cent in weight. 


\section{STOMACH AND INTESTINES}

The stomach and intestines (including mesentery and pancreas) together with their content (table 3) form an average of about 5.2 per cent of the body weight in the acute inanition series, and 6.3 per cent in the chronic inanition series. Since the average normal for the initial body weights is about 9.0 per cent (Jackson '13)', it is evident, as might be expected, that the stomach and intestines with contents have lost weight in relatively much greater proportion than has the body as a whole. The loss affects not only the contents, but the empty tract, which has apparently decreased from about 6.0 per cent (normal at the initial body weight) of the body weight to 3.25 per cent (acute inanition series) or 3.5 per cent (chronic series). There is apparently not much difference in this respect between the chronic and acute series. A relatively small part of the loss is in the mesenteric fat.

In terms of absolute weight, taking Hatai's ('13) curve for the normal, there is apparently a decrease in the weight of the empty alimentary canal from about 11.65 to 5.01 grams in the acute inanition series, and from 10.70 to 4.54 grams in the chronic series. This would correspond to a loss of about 57 per cent in each series.

Data in the literature are very scarce concerning changes in weight of the alimentary canal during inanition. According to Falck ('54), the loss appears to be nearly proportional to that of the entire body (relative weight increasing from 8.4 to 8.7 per cent). This appears to be true also for the cat according to Sedlmair ('99), although a much smaller loss was found by Voit ('66). Unpublished data on a series of steers (Missouri Agricultural Experiment Station) indicate that the relative weight of the (empty) intestines (without fat) is variable, but tends to be greater in thin than in fat animals. 


\section{SUPRARENAL GLANDS}

The suprarenal glands must be considered separately in the sexes on account of a difference in relative weight (Jackson '13). In normal rats corresponding to the initial body weights of the present series, the average for the suprarenal glands of the male is about 0.17 per cent of the body weight, and for the female about 0.26 per cent. The four females of the acute inanition series (none present in the chronic series) show an average of 0.30 per cent of the body weight (table 3 ), but the number is too small for definite conclusions. The males show an increase (from 0.17 per cent) to an average of 0.25 per cent in both acute and chronic inanition series (table 3). It would therefore appear that the loss in absolute weight has been less than in the body as a whole in the female with little or no loss in the male.

In terms of absolute weight, taking Hatai's ('13) curve for' the normal, it appears that in the male rat the suprarenals have increased from about 0.0390 to 0.0396 grams (gain of 1.5 per cent) in the acute inanition series; and decreased from about 0.0360 to 0.0328 grams (loss of 8.9 per cent) in the chronic series. The apparent increase during acute inanition is probably not significant. A larger number of observations is necessary to determine the matter.

No data concerning the weight of the suprarenal glands during inanition have been found in the literature, although Traina ('04) cites several investigations on the histological changes.

\section{KIDNEYS}

The kidneys (table 3 ) in the acute inanition series form an average of 0.97 per cent of the body weight and in the chronic series 1.00 per cent. According to Jackson ('13) the normal for the initial body weights would average about 0.95 per cent (although Hatai's data would place it at about 0.84 per cent). It therefore appears that the kidneys have lost weight to nearly the same extent relatively as the body in general, thus gaining but slightly in relative (percentage) weight. 
If Hatai's ('13) curve be taken as the normal, in absolute weight the kidneys would apparently decrease from about 2.04 to 1.520 grams (a loss of 25.5 per cent) during acute inanition; and from 1.80 to 1.317 grams (a loss of 26.8 per cent) in the chronic inanition series. If my data indicating a higher normal were taken, the loss would be correspondingly greater.

Considering the importance of the kidneys, there is in the literature a surprising lack of data concerning their weight during inanition. That they lose in weight relatively somewhat less than the body as a whole (thus gaining in percentage weight) is indicated in the pigeon (Chossat '43), cat (Voit '66) and dog (Falck '54). There appears also a slight relative increase in the kidney weight of thin steers compared with fat (data from Missouri Agricultural Experiment Station). On the other hand, Sedlmair's ('99) data for starved cats indicate no change in relative (percentage) weight in one case and a slight decrease in another.

\section{GONADS}

a. Female. The two observations recorded for the weight of the ovaries, 0.051 per cent and 0.033 per cent of the body weight are both above the normal average ( 0.025 per cent), but are of course entirely too few to be significant.

b. Male. At the age of one year (body weight, 210 grams) the normal testes and epididymi form an average of about 1.20 per cent of the body weight, of which approximately one-fourth $(0.30$ per cent) belongs to the epididymi, and three-fourths $(0.90$ per cent) to the testis (Jackson '13). Hatai's ('13) data would put the testis a little higher (about 1.05 per cent). In the acute inanition series (table 3) the average relative weight for the testes is 1.12 per cent, and for the epididymi is 0.39 per cent of the body weight. In the chronic series, the average for the testes is 1.02 per cent, and for the epididymi 0.33 per cent. It would therefore appear that during inanition the loss in weight of both testes and epididymi is relatively not very different from that in the body as a whole, and is (like that of the majority of the viscera) more marked in chronic than in acute 
inanition. On account of the variability of these organs, however, more data are needed before final conclusions can be justified.

In terms of absolute weight, taking Hatai's ('13) data for the normal at the initial body weight, the testis would appear to decrease from 2.50 to 1.756 grams (a loss of 29.8 per cent) in the acute inanition series; and from 2.27 to 1.355 grams (a loss of 40.3 per cent) in the chronic inanition series.

Although numerous investigations have been made upon the histological changes in the gonads during inanition (Traina '04), the only observations found concerning their weight are that by Falck ('54) showing the relative (percentage) weight of the testis in the dog to remain apparently unchanged, and that by (Voit '66) showing a relative decrease in the testis of the cat.

\section{HYPOPHYSIS}

In the case of the hypophysis, as with the suprarenal glands, there is normally a sexual difference to be considered (Hatai '13). When the data in table 3 are compared with Hatai's chart 10, it will be found that the absolute weights of the hypophysis, in both acute and chronic inanition, correspond fairly well with those of the normal gland at the final body weight. That is, the weight of the hypophysis during inanition has apparently decreased in nearly the same proportion as the whole body, so the relative weight is but little changed. As calculated from Hatai's data, the (male) hypophysis would form about 0.0036 per cent of the body at the average initial body weight, as compared with 0.0043 per cent found in the acute inanition series, and 0.0045 per cent in the chronic series.

In terms of absolute weight, the (male) hypophysis has apparently decreased from about 0.0093 to 0.0069 gram, the average of the acute inanition series (loss of 26.1 per cent); and from 0.0079 to 0.0059 gram (loss of 25.3 per cent) in the chronic inanition series. A larger number of observations would of course be necessary to determine the result with precision.

No data have been found in the literature concerning the weight of the hypophysis during inanition. 


\section{DISCUSSION}

The changes in the average relative weights of the various organs and systems as a result of inanition in the adult albino rat are summarized in table 2.

While no great emphasis can be laid upon the exactness of the figures shown in table 2 , it is evident that with respect to relative loss in weight during inanition, the organs may be divided into three groups. In the first group, which includes the suprarenals, thyroid, skeleton, eyeballs, spinal cord and brain, and thymus, there is but little (if any) loss in absolute weight during inanition, and a corresponding increase in relative (percentage) weight. In general, there is a relatively greater loss during chronic

TABLE 2

\begin{tabular}{|c|c|c|c|c|c|}
\hline \multirow{2}{*}{ ORGAX OR SYSTEM } & \multirow{2}{*}{$\begin{array}{l}\text { NOHMAL PERCENTAGE } \\
\text { OF BODY AT INITIAL } \\
\text { BODY WEIGHT }\end{array}$} & \multicolumn{2}{|c|}{$\begin{array}{l}\text { PERCENTAGE OF BODY } \\
\text { AFRER INANITION }\end{array}$} & \multicolumn{2}{|c|}{$\begin{array}{l}\text { 2LERCENTAGE LOSS OF ORGAN } \\
\text { DURING INANITION }\end{array}$} \\
\hline & & Acute & Chronic & Acute & Chronic \\
\hline \multicolumn{6}{|l|}{ Suprarenals } \\
\hline (male).... & 0.0170 & 0.0220 & 0.0260 & $+1.5(?)$ & -8.9 \\
\hline Thymus........ & 0.0200 & 0.0200 & 0.0210 & $0(?)$ & $0(?)$ \\
\hline Thyroid gland... & $0.0150(0.016)$ & 0.0230 & 0.0200 & $0(?)$ & -21.8 \\
\hline Spinal cord..... & $0.2500(0.290)$ & 0.4000 & 0.4300 & $0(?)$ & -4.0 \\
\hline \multicolumn{6}{|l|}{ Ligamentous } \\
\hline skeleton....... & 10.0000 & 15.0000 & 16.4000 & -0.4 & $+1.8(?)$ \\
\hline Eyeballs........ & $0.1200(0.130)$ & 0.1900 & 0.2000 & -4.4 & -5.8 \\
\hline I3rain. ......... & $0.7800(0.870)$ & 1.1700 & 1.3300 & -5.1 & -6.6 \\
\hline Kidneys........ & 0.9500 & 0.9600 & 1.0000 & -25.5 & -26.8 \\
\hline Hypophysis...... & 0.0036 & 0.0043 & 0.0045 & -26.1 & -25.3 \\
\hline Heart......... & 0.4300 & 0.4400 & 0.4200 & -27.7 & -32.8 \\
\hline 'Testes...... & 10.9000 & 1.0600 & 1.0100 & -29.8 & -40.3 \\
\hline Lungs.... . & 0.6000 & 0.6100 & 0.5500 & -30.9 & -40.0 \\
\hline Musculature.... & 45.0000 & 47.5000 & 43.0000 & -30.9 & -40.8 \\
\hline Integument...... & 18.0000 & 19.1000 & 17.8000 & -31.2 & -38.5 \\
\hline Whole body. .... & 100.0000 & 100.0000 & 100.0000 & -33.9 & -36.1 \\
\hline Spleen.......... & 0.2700 & 0.2100 & 0.3100 & -51.0 & -29.0 \\
\hline $\begin{array}{l}\text { Stomach-intes- } \\
\text { tines. }\end{array}$ & 6.0000 & 3.4000 & 35000 & -570 & -570 \\
\hline Liver........... & 4.5000 & 3.1000 & 4.0000 & -58.0 & -43.0 \\
\hline
\end{tabular}


inanition, which is especially marked in the case of the thyroid gland. The thymus, having already undergone age involution, is affected but slightly, if at all.

In the second group, which includes the kidneys, hypophysis, heart, testes, lungs, musculature and integument, the loss in absolute weight during inanition is more nearly in proportion to that of the whole body, so their relative (percentage) weight is usually not greatly changed. In all except the hypophysis, however, the loss is relatively greater during chronic inanition. Especially the lungs, testes, integument and musculature appear to lose markedly during chronic inanition.

In the third group, including the spleen, liver and alimentary canal, the loss in absolute weight is relatively much greater than in the body as a whole, so they decrease in relative as well as in absolute weight. The liver and spleen are exceptional, however, in that their loss is apparently relatively greater in acute than in chronic inanition. In fact, in chronic inanition the spleen apparently belongs with the second group.

The variability of the organs as to loss of weight during inanition has been explained in two ways: Manassein ('69) noted that those organs which are most active in the organism lose least during inanition. A more rational explanation is that of Paschutin ('81), according to whom the various organs lose in proportion to their storage content of available food supply. The various proteids, fats and carbohydrates are dissolved and carried away by the circulation at different times and with different degrees of rapidity. Thus the variability in the loss of weight in different organs and in different types of inanition would be ultimately explained primarily upon a chemical basis.

\section{SUMMARY}

The principal results of the present paper may be briefly summarized as follows:

1. During both acute and chronic inanition there is apparently a slight increase in the ratio of tail length to body length. This is probably due to a decrease in the trunk length during inanition. 
2. The head and fore limbs during inanition lose relatively less than the body as a whole, and therefore increase in relative (percentage) weight. The hind limbs nearly maintain their original relative weight (slight increase during acute inanition), while the trunk decreases in relative weight.

3. Of the systems-integument, skeleton, musculature, viscera and 'remainder'-the integument and musculature lose relatively in nearly the same proportion as the whole body, slightly less during acute inanition and slightly more during chronic inanition. The skeleton nearly maintains its original absolute weight, and therefore increases markedly in relative (percentage) weight. There is a marked decrease in the 'remainder,' probably due chiefly to loss of fat. The visceral group as a whole undergoes little change in relative weight, showing a slight decrease during acute inanition. This decrease is due to the large size of the liver, which undergoes a greater loss in acute than in chronic inanition. The majority of the viscera, on the other hand, show a greater loss during chronic inanition.

4. As to relative loss of weight during inanition, the individual viscera may be divided into three groups: (1) the suprarenal glands, thyroid glands, eyeballs, spinal cord and brain lose but very little (if any) in absolute weight, and therefore increase correspondingly in relative (percentage) weight. The thymus has already undergone age involution, and is therefore unaffected. (2) The kidneys, heart, lungs, hypophysis and testes lose more nearly in proportion to the entire body (in general, somewhat more during chronic inanition), and therefore do not change greatly in relative (percentage) weight. (3) The spleen (in acute inanition), liver and alimentary canal (both empty and with contents) lose relatively much more heavily than the whole body, and therefore decrease in relative (percentage) as well as in absolute weight. 


\section{LITERATURE CITED}

Aron, Hans 1911 Nutrition and growth. I. Philippine Journal of Science, B. Medical Sciences, vol. 6 , no. 1 .

Aschoff, L. 1911 Pathologische Anatomie, Bd. 1, Allg. Theil, S. 41.

von BECHTEREw, W. 1895 Ueber den Einfluss des Hungerns auf die neugebor. enen Thiere, insbesondere auf das Gewicht und die Entwickelung des Gehirns. Neurol. Centralblatt, Jahrg., Bd. 14, pp. 810-817.

BELL, E. T. 1911 The interstitial granules of striated muscle and their relation to nutrition. Internat. Monatschr. f. Anat. u. Physiol., Bd. 28, H. 10-12.

BitsCH 1895 Pathologische-anatomische Veränderungen der Netzhaut des Hundes beim Hungern (mit und ohne Wasser). Dissertation, St. Petersburg (cited by Mühlmann '99).

BowIv, M. 1880 Beiträge zur Frage über die Trockenernährung. Dissertation, St. Petersburg (cited by Mühlmann '99).

CEsa-BIANCHI, D. 1909 Leber-und Nierenzellen während der Verhungerung. Frankf. Zeitschr. f. Pathol., Bd. 3.

Chossat, Chardes 1843 Recherches expérimentales sur l'inanition. Mémoire auquel 1'Académie des Sciences a décerné en 1841 le prix de physiologie expérimentale. Extrait des mémoires de l'academie royale des sciences. Tome 8 des savants étrangers. Paris, Imprimiere Royal.

Donaldson, Henry H. 1908 A comparison of the albino rat with man in respect to the growth of the brain and of the spinal cord. Jour. Comp. neur., vol. 18, no. 4.

1909 On the relation of the body length to the body weight and to the weight of the brain and of the spinal cord in the albino rat. Jour. Comp. neur., vol. 19, no. 2.

1911 The effect of underfeeding on the percentage of water, on the ether-alcohol extract, and on medullation in the central nervous system of the albinl rat. Jour. Comp. Neur., vol. 21, no. 2.

FalcK, C. P. 1854 Beiträge zur Kenntnis der Wachstumsgeschichte des Tierkörpers. Virchow's Archiv, Bd. 7.

GAGLIO, G. 1884 Sulla alterazioni istologiche e funzionali dei muscoli duranti l'inanizione. Arch. Sci. med., tome 7, pp. 301-310 (cited by Morgulis '11).

HaRMS, W. 1909 Ueber den Einfluss des Hungerns auf die Wirbelsäule der Tritonen. Verh. deutsch. Zool. Ges. 19 Vers. Frankfurt a.M., pp. $307-312$.

HATAI, S. 1904 The effect of partial starvation on the brain of the white rat. Amer. Jour. Physiol., vol. 12, no. 1. 
HAtaI, S. 1908 Preliminary note on the size and condition of the central nervous system in albino rats experimentally stunted. Jour. Comp. Neur., vol. 18, no. 2.

1913 On the weights of the abdominal and the thoracie viscera, the sex glands, ductless glands and the eyeballs of the albino rat (Mus Norvegicus albinus) according to body weight. Am. Jour. Anat., vol. 15 , no. 1 .

1914 On the weight of the thymus gland of the albino rat (Mus Norvegicus albinus) according to age. Am. Jour. Anat., vol. 16, no. 2.

JACKson, C. M. 1904 Zur Histologie und Histogenese des Knochenmarkes. Archiv f. Anat. u. Physiol. (Anat. Abth.).

1913 Postnatal growth and variability of the body and of the various organs in the albino rat. Am. Jour. Anat., vol. 15, no. 1.

1915 Changes in the relative weights of the various parts, systems and organs of young albino rats held at constant body-weight by underfeeding for various periods. Jour. Exp. Zoöl., vol. 19, no. 2 .

JACKsON, C. M., and LowREY, L. G. 1912 On the relative growth of the component parts (head, trunk and extremities) and systems (skin, skeleton, musculature and viscera) of the albino rat. Anat. Rec., vol. 6, no. 12.

Jonson, Arvid 1909 Studien über die Thymusinvolution. Die akzidentelle Involution bei Hunger. Archiv f. mikr. Anat., Bd. 73.

LASAREw, N. 1895 Zur Lehre von der Veränderung des Gewichts und der zelligen Elemente einiger Organe und Gewebe in verschiedenen Perioden des vollständigen Hungerns. Dissertation, Warschau (eited by Mühlmann '99).

Lowrey, L. G. 1913 The growth of the dry substance in the albino rat. Anat. Rec., vol. 7, no. 9 .

Lustic, A. 1902 Patologia generale, vol. 2, Milano (cited by Traina '04).

Manassein, W. 1869 Beiträge zur Frage über das Hungern. Dissertation, St. Petersburg (cited by Mühlmann '99).

Morgutis, S. 1911 Studies of inanition in its bearing upon the problem of growth. I. Archiv f. Entw., Bd. 32, H. 2.

Mühlmann, M. 1899 Russische Literatur über dio Pathologie des Hungerns (der Inanition). Zusammendes Referat. Centralbli f. allg. Pathologie, Bd. 10, pp. $160-220 ; 240-242$.

Paschutin, W. 1881 Vorlesungen über allgemeine Pathologie. II. Theil. St. Petersburg (cited by MühImann '99).

Pfeiffer, L. 1887 Ueber den Fettgehalt des Körpers und verschiedener Theile desselben bei Magern und fetten Tieren. Zeitschr. f. Biol., Bd. 23 (N. F. Bd. 5). 
SEDlmair, A. C. 1899 Ueber die Abnahme der Organe, insbesondere der Knochen, beim Hunger Zeitschr. f. Biol., Bd. 37 (N. F. Bd. 19).

Stschastny, S. 1898 Veränderungen der inneren Organe eines Menschen, der nach 35 tägiger Hungerdauer gestorben war. (Russ.) Archiv f. Pathol. etc., Bd. 5 (cited by Mühlmann '99).

Traina, R. 1904 Ueber das Verhalten des Fettes und der Zellgranula bei chronischen Marasmus und akuten Hungerzuständen. Beitr. z. path. Anat. u. allg. Pathol., Bd. 35.

VoIt, CARL 1866 Ueber die Verschiedenheiten der Eiweisszersetzung beim Hungern. Zeitschr. f. Biol,, Bd. 2.

Voit, ERwiN 1905 a Die Abnahme des Sheletts und der Weichteile bei Hunger Zeitschr. f. Biol., Bd. 46 (N. F. Bd. 28).

$1905 \mathrm{~b}$ Welchen Schwankungen unterliegt das Verhältnis Organgewichte zum Gesamtgewicht des Tieres? Zeitschr. f. Biol., Bd. 46 (N. F, Bd, 28).

WeIske, H. 1895 Weitere Beiträge zur Frage über die Wirkung eines Futters mit sauren Eigenschaften auf den Organismus, insbesondere auf der Skelett. Zeitschr. f. physiol. Chemie, Bd. 40. 


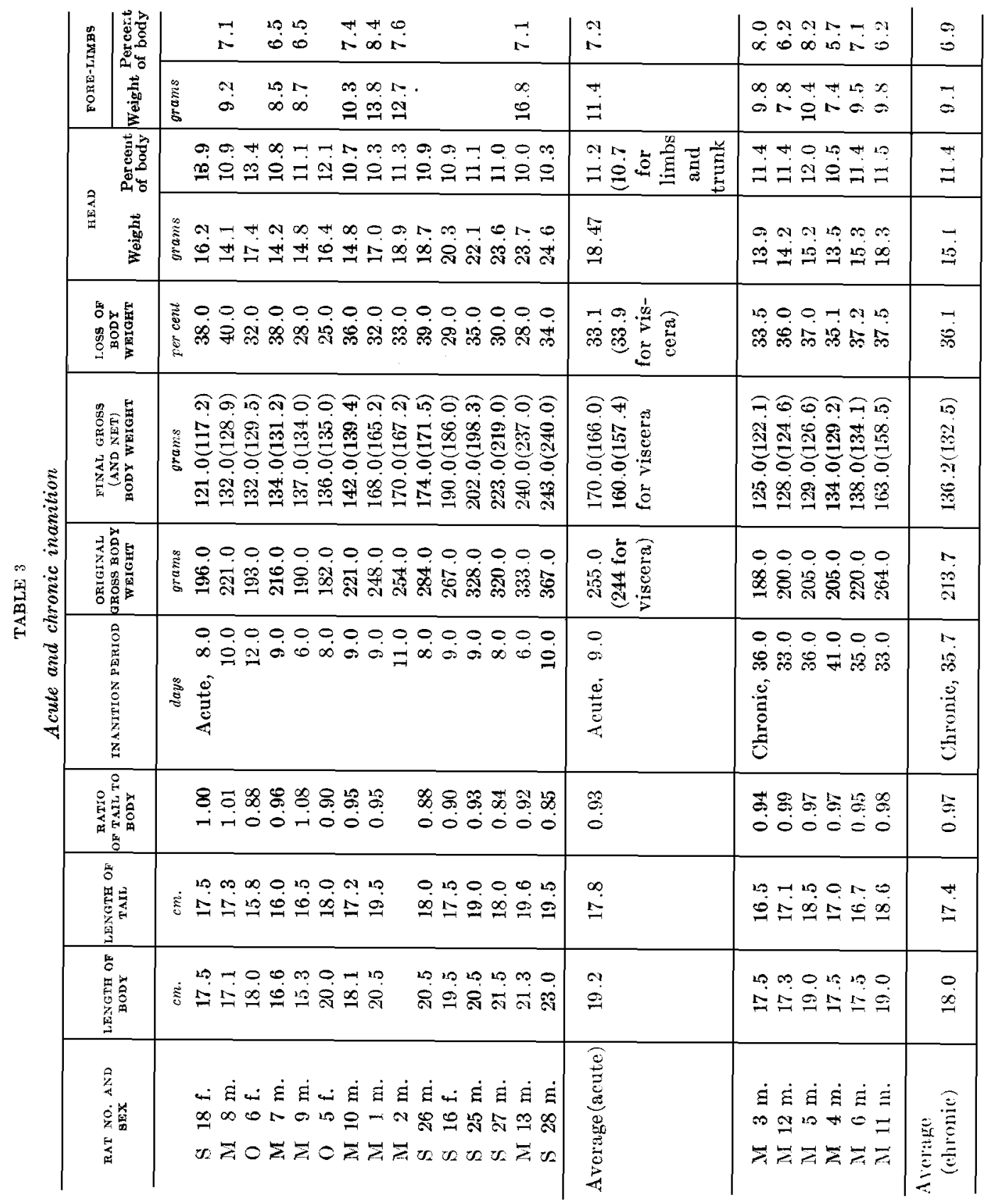




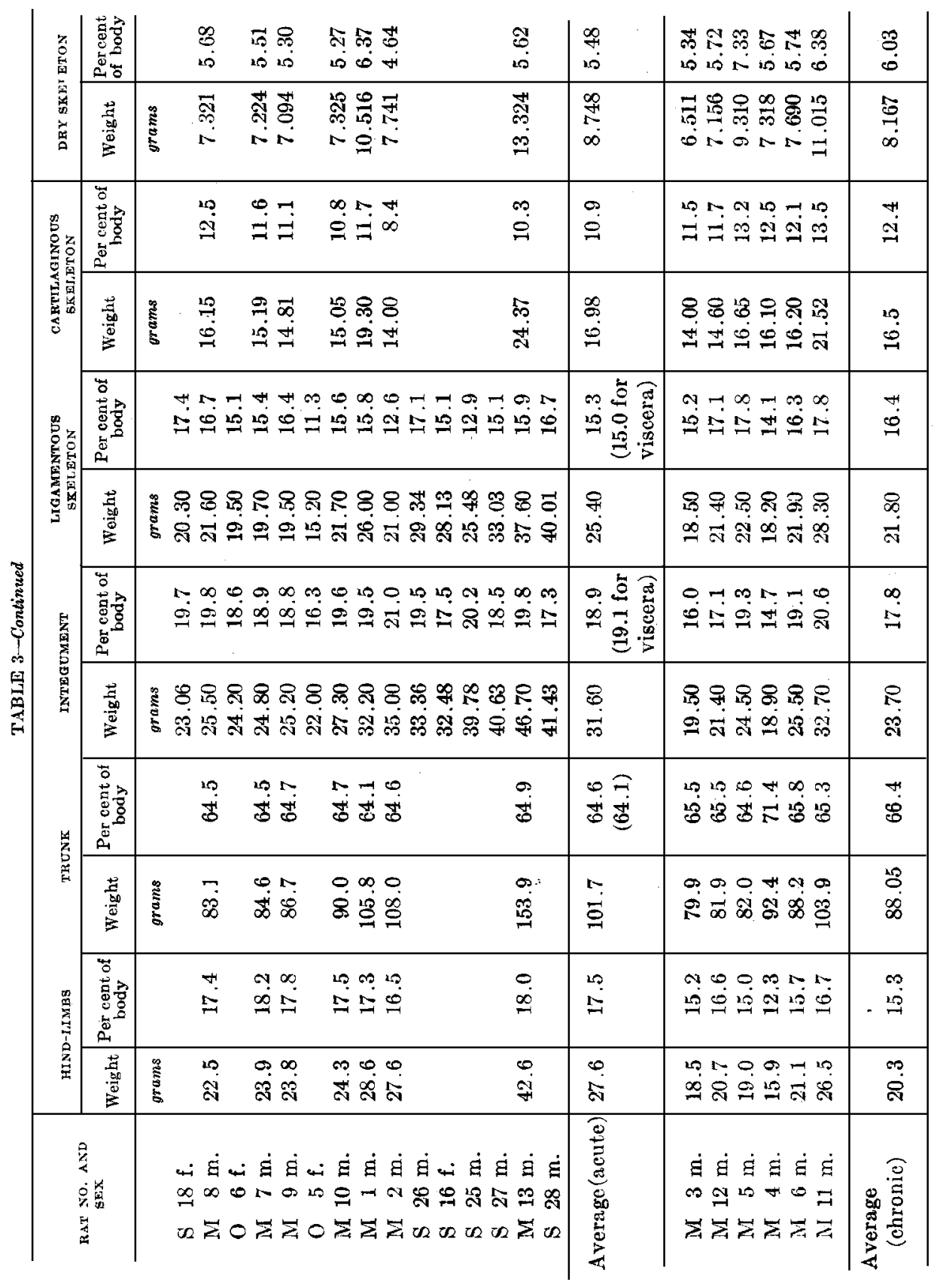




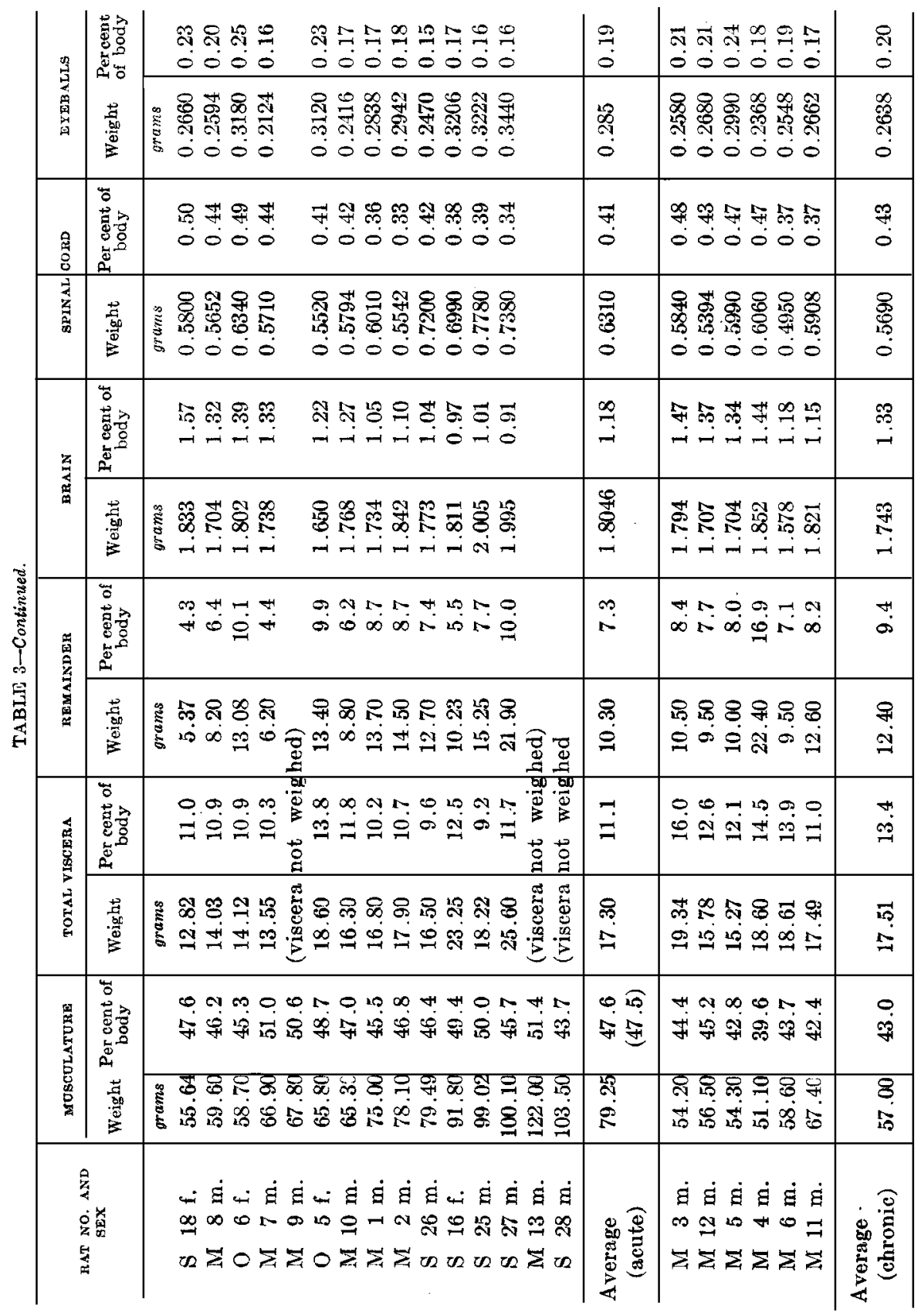




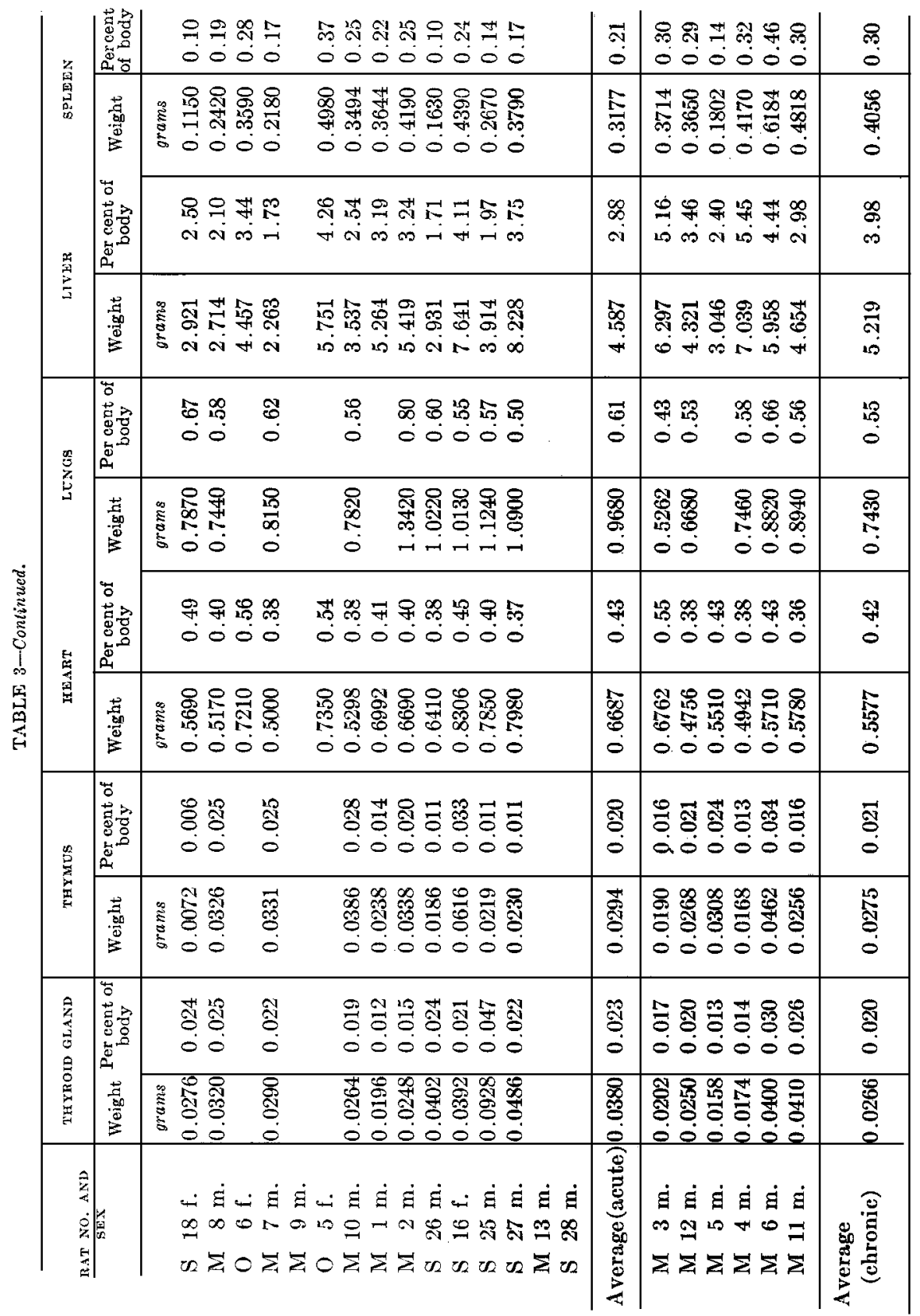




\begin{tabular}{|c|c|c|c|c|c|c|c|}
\hline \multirow{2}{*}{ 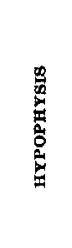 } & 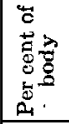 & $\begin{array}{l}\sqrt{5} \\
8 \\
0\end{array}$ & $\begin{array}{l}\text { क्ष } \\
\text { 8े } \\
2\end{array}$ & 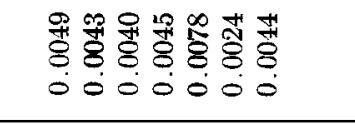 & $\begin{array}{l}\text { क्ष } \\
8 \\
0 \\
0\end{array}$ & 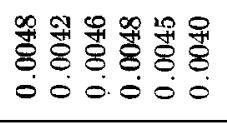 & $\begin{array}{l}\text { 管 } \\
\text { : } \\
0\end{array}$ \\
\hline & 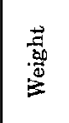 & 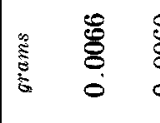 & 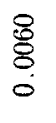 & 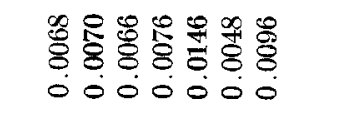 & 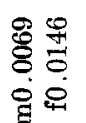 & 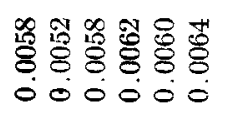 & $\begin{array}{l}\stackrel{8}{8} \\
\stackrel{8}{8} \\
0\end{array}$ \\
\hline \multirow{2}{*}{ 商 } & 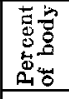 & $\stackrel{\mathscr{m}}{\circ}$ & $\stackrel{n}{\infty}$ & 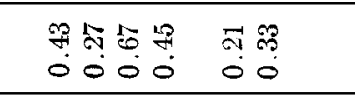 & $\stackrel{\leftrightarrow}{\circ}$ & 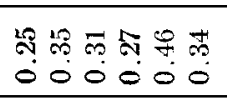 & 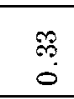 \\
\hline & 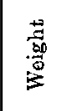 & 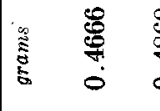 & 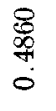 & 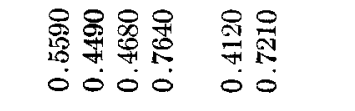 & $\begin{array}{l}5 \\
\substack{0 \\
0 \\
0} \\
0\end{array}$ & 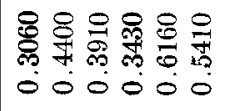 & 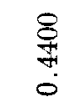 \\
\hline \multirow{2}{*}{ 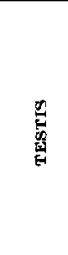 } & 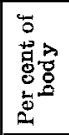 & & 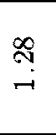 & 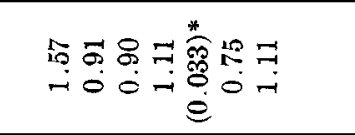 & $\stackrel{1}{\cong}$ & 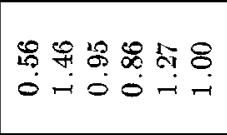 & $\stackrel{g}{0}$ \\
\hline & 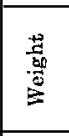 & 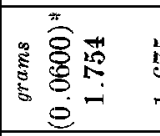 & $\stackrel{10}{10}$ & 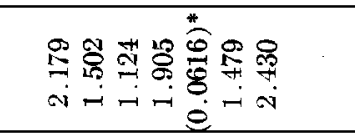 & 悉 & 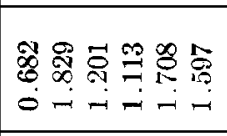 & - \\
\hline \multirow{2}{*}{$\begin{array}{l}\infty \\
\frac{\pi}{2} \\
\frac{\pi}{4}\end{array}$} & 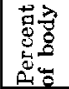 & 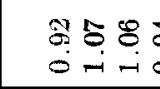 & & 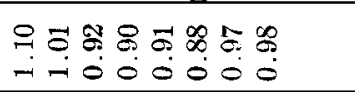 & $\stackrel{5}{0}$ & 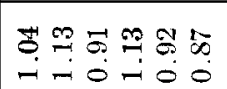 & $\underset{-i}{8}$ \\
\hline & 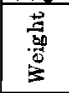 & 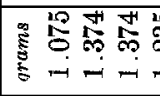 & & 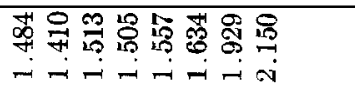 & 赵 & 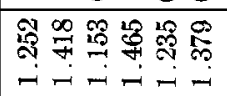 & 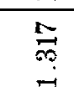 \\
\hline \multirow{2}{*}{ 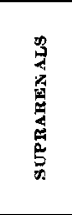 } & 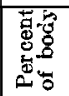 & 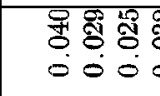 & & 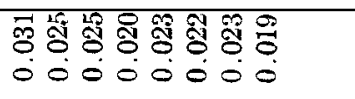 & 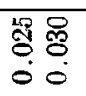 & 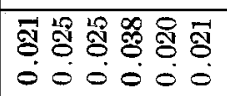 & $\begin{array}{l}18 \\
8 \\
0\end{array}$ \\
\hline & 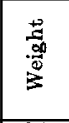 & 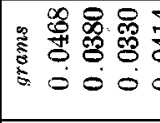 & & 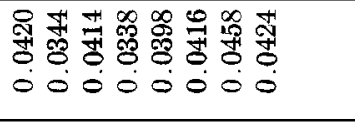 & 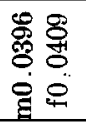 & 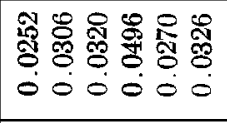 & \begin{tabular}{l}
$\infty$ \\
\multirow{N}{*}{} \\
$\dot{0}$
\end{tabular} \\
\hline \multirow{2}{*}{ 罂 } & 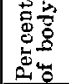 & $\begin{array}{l}\infty \\
\infty \\
\infty\end{array}$ & & 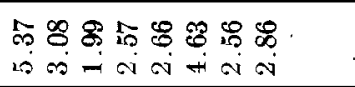 & מิ & 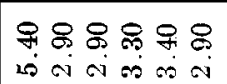 & 品 \\
\hline & 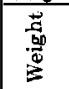 & 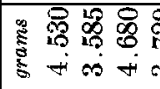 & & 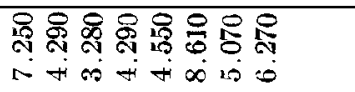 & 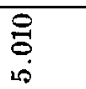 & 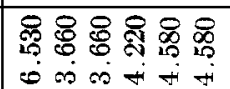 & 早 \\
\hline \multirow{2}{*}{ 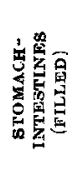 } & 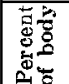 & 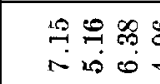 & & 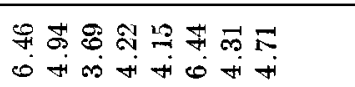 & $\vec{\sim}$ & 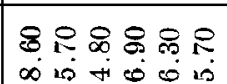 & ఠి \\
\hline & $\frac{\sqrt{3}}{30}$ & 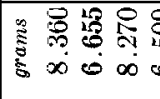 & 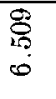 & 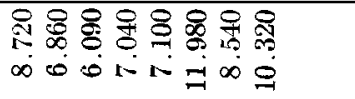 & 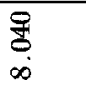 & 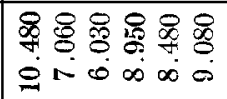 & $\begin{array}{c}10 \\
\infty \\
\infty \\
\infty\end{array}$ \\
\hline \multirow{2}{*}{ 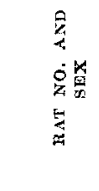 } & & \multirow{2}{*}{\multicolumn{3}{|c|}{ 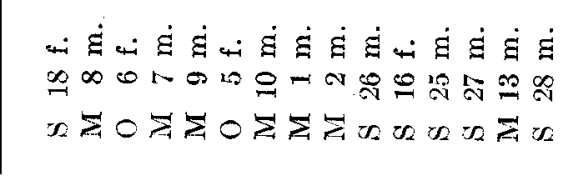 }} & $\stackrel{0}{\oplus}$ & 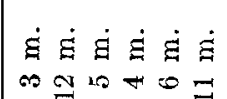 & $\widehat{\Xi}$ \\
\hline & & & & & 震总 & 之些元三元 & 胥 \\
\hline
\end{tabular}

